\title{
El carácter visual fundamental de todo conocimiento. Teoría de la imagen y teoría perspectivista en Fichte
}

\section{Christoph Asmuth}

Traductor. Héctor Arrese Igor

\section{(2) OpenEdition}

\section{Journals}

Edición electrónica

URL: http://journals.openedition.org/ref/416

ISSN: 2258-014X

Editor

EuroPhilosophie Editions

\section{Referencia electrónica}

Christoph Asmuth, «El carácter visual fundamental de todo conocimiento. Teoría de la imagen y teoría perspectivista en Fichte », Revista de Estud(i)os sobre Fichte [En línea], 6 | 2013, Publicado el 03 junio 2013, consultado el 08 septiembre 2020. URL : http://journals.openedition.org/ref/416

Este documento fue generado automáticamente el 8 septiembre 2020.

(c) EuroPhilosophie 


\section{El carácter visual fundamental de todo conocimiento. Teoría de la imagen y teoría perspectivista en Fichte}

\section{Christoph Asmuth}

Tradución : Héctor Arrese Igor

\section{NOTA DEL AUTOR}

Quiero expresar mi mayor agradecimiento al Prof. Dr. Héctor Oscar Arrese Igor por su traducción.

1 La pluralidad de perspectivas se ha convertido en un problema candente en nuestros días, ante el cual la filosofía no puede permanecer impasible. El perspectivismo tiene diversas facetas. ${ }^{1}$ En última instancia la globalización económica es una variante del perspectivismo. Desde una mirada práctica un pluralismo de perspectivas lleva a la compatibilidad entre valores diferentes, heterogéneos, pero también a la pérdida de criterios inequívocos. Desde un punto de vista teorético éste conduce a la compatibilidad entre perspectivas heterogéneas, a una coexistencia de modos de conocer y de mundos del conocimiento. Al mismo tiempo las demarcaciones son más importantes y significativas que nunca - al menos en el campo de la normatividad. El problema es ,dicho en general, un problema de la unidad y de la pluralidad o, dicho de otra manera: el pluralismo plantea el problema de cómo una pluralidad de perspectivas es compatible con la unidad de perspectivas. Al mismo tiempo se plantea inevitablemente la pregunta por las pretensiones de verdad y de validez. Evidentemente el perspectivismo lleva a la disolución del concepto de verdad convencional o, al menos, a su relativización. El perspectivismo es al mismo tiempo un relativismo pluralista. Visto de este modo el relativismo pluralista parece ser una 
enfermedad intelectual, algo para "caracteres débiles y corvos". Pero nosotros nos hemos acomodado bien hoy en día a ello y nos resulta confortable. O: el perspectivismo relativista en su forma pragmática se ha vuelto algo irrenunciable.

Este problema podría formularse también de modo totalmente abstracto de la siguiente manera: ¿es el perspectivismo mismo una perspectiva con una pretensión de validez y de verdad? Desde el punto de vista de Fichte, uno se siente inclinado a responder a la pregunta inmediatamente de modo negativo, con la referencia a la auto-contradicción. Porque ¿cómo podría una visión del mundo ser al mismo tiempo muchas visiones del mundo, esto es cómo puede ser plural y relativa? Además éstas deberían relacionarse una con la otra, independientemente de cuán plurales sean, y con ello pertenecer a un mundo. Wolfgang Cramer ha reclamado para Fichte lo que ningún otro pensador de su tiempo, ni siquiera el mismo Hegel, ha visto con tal claridad como él, a saber, que un concepto de unidad yace por debajo de toda pluralidad. ${ }^{2}$ Más aún: Fichte ha afirmado, a partir de la ampliación de la teoría kantiana del juicio hacia una teoría de la consciencia más abarcadora, que la totalidad del conocimiento se basa ante todo en una función de unidad. ${ }^{3}$ Todo su pensamiento filosófico parte de la concepción de que cada momento produce la unidad, que es efectiva y está activa en toda síntesis, esto es en toda estructura cognitiva. ${ }^{4}$

¿Es el perspectivismo pluralista él mismo una concepción del mundo? Fácilmente podría considerarse a esta pregunta como sofística o polémica, al ser planteada en entre especialistas de la filosofía de Fichte. Y yo creo que podría bastarme con decir obviedades. Servirse del pensador de la unidad, de la unidad orgánica y absoluta, para usarlo contra la pluralidad y la diversidad, sería efectivamente como llevar lechuzas a Atenas. Puede considerarse justo celebrar a Fichte como el protagonista de una concepción, de acuerdo con la cual debería tratarse únicamente de reconducir toda la pluralidad a la unidad absoluta. Pero obrar de este modo no es hacer algo inteligente. Yo temo que con ello no se haría justicia al planteamiento principal del problema. El pluralismo parece ser real, y la perseverancia en la unidad, en la unidad pura, sea ésta la del ser, la razón, el mundo o la ciencia, se parece más bien a la obstinación de un niño que no quiere crecer, que prefiere cerrar los ojos antes que mirar a la realidad. Para decirlo sin ambages: yo creo que el problema del pluralismo es por un lado significativamente más antiguo que la modernidad, si bien no había surgido históricamente con la agudeza con la que hoy somos conscientes de la cuestión. De modo correspondiente es también más tenaz. Yo estoy por otro lado fuertemente convencido de que Fichte fue uno de los primeros pensadores de la modernidad que por primera vez respondieron al problema del pluralismo.

4 Mi supuesto es que la pregunta no puede probablemente ser formulada de este modo: ¿es el perspectivismo pluralista él mismo una concepción del mundo? Esta pregunta fracasa por un lado ante la evidencia fáctica de una multiplicidad de perspectivas y valoraciones. Por otro lado la pregunta toma con liviandad la relación entre la unidad y la pluralidad de perspectivas y de ese modo deja fuera de consideración el esfuerzo espiritual enorme de la fundamentación y la comprensión de la perspectiva como forma fundamental del conocimiento. El pluralismo -en el sentido mencionadorealmente es un caso precedente de una argumentación trascendental filosófica. En consecuencia no se pone en cuestión la afirmación de la existencia o la autorización o validez normativas, sino las condiciones de posibilidad. Según Fichte la pregunta debe decir: ¿cómo es posible un pluralismo de perspectivas en general? 
5 Y justamente en este sentido es que la teoría de Fichte se vuelve un catalizador del movimiento romántico. Se trata de este sentido especial, que consiste en una liberación del mono-perspectivismo de la metafísica ilustrada, junto con una praxis revolucionaria proto-socialista y el impulso hacia una filosofía nueva dirigida a la certeza científica, todo lo cual fue retomado por los románticos. En efecto, Schelling, Novalis, Schlegel, Solger: todos ellos desarrollan su pensamiento a partir del nuevo desarrollo de la filosofía efectuado por Fichte. Pero también lo dejan a él por detrás de ellos, porque ven la necesidad de desarrollar una nueva forma de filosofía.

\section{La teoría de los puntos de vista en El camino a la vida bienaventurada}

6 En El camino a la vida bienaventurada (AsL) Fichte desarrolla su teoría de las cinco concepciones del mundo. El mundo surge en sus formas y estructuras infinitas por medio del concepto y la reflexión. Ciertamente que sobre este mundo yace un smog de indiferencia. El mundo está lleno de estructuras, pero ¿qué significan? Ellas pasan por delante; ¿qué debe hacer el Yo con ellas? Allí hay un mundo con múltiples contenidos, pero no le interesa a nadie. Da lo mismo si está allí o no. Sólo se lo contempla y por medio del acto de mirar es que viene a ser. Sin embargo él no es nada para el Yo, sólo un mundo de esquemas, las sombras de un sueño, imágenes sin sentido. ${ }^{5}$

7 A este mundo le falta la dimensión de la acción, que el Yo sea un ser activo y pensante, que debe orientarse en el mundo y debe evaluarlo -eso no tiene lugar en la pluralidad de los contenidos del mundo. No sólo el mundo está partido en una pluralidad de contenidos, sino que es comprendido y contemplado de diversas maneras. Fichte enumera cinco visiones del mundo. ${ }^{6}$ Estas visiones del mundo no pueden encontrarse por medio de la experiencia. Se pueden explorar ya antes de toda experiencia, independientemente de ella, a priori. El fundamento de ello reside en que las visiones del mundo se diferencian fundamentalmente en que cada una pone la realidad en algo distinto. Cada visión del mundo es caracterizada y determinada de modo particular por medio de lo que es diferente en cada caso. En la quinta lección de su AsL Fichte dice:

Al hecho de que uno tenga un punto de vista fijo para su visión del mundo, le corresponde que uno pone lo real, lo independiente y la raíz del mundo en un punto fundante determinado e inalterable, a partir del cual uno deduce el resto, únicamente como participando en la realidad del primero y sólo establecido de modo mediato. (AsL, GA I/9, 108)

8 Una visión del mundo se arraiga en un punto de vista, se ancla en aquello que considera que es lo único real y considera al mundo comprendido a partir de este fundamento. La realidad es su punto fijo, a partir del cual ella desarrolla todo, el centro a partir del cual ella actúa.

9 A la vez el hecho de que las visiones del mundo no sean equivalentes posee un significado muy grande. Las visiones del mundo constituyen una jerarquía. Ellas no coexisten unas junto a otras, sino que están subordinadas la una a la otra. Por un lado, esto es importante ante todo porque Fichte de este modo corrige posiciones anteriores. Por otro lado estas perspectivas llevan a cabo, por medio de esta ordenación, una crítica a Kant y a Jacobi. La posición de Fichte está aquí determinada inequívocamente: 
una concepción del mundo más elevada no tolera junto a sí a la inferior, sino que cada superior destruye a la que es inferior a ella -en cuanto que es el punto de vista más elevado y absoluto- y la subordina. (AsL, GA I/9, 109) aquella que le es inferior. No hay ninguna excepción. Y destruirlas significa: una visión del mundo se vuelve inválida en cuanto que absoluta en su significado, ella está subordinada a otra, ahora convertida en absoluta. En última instancia esto implica que sólo existe una concepción del mundo absoluta, a la cual están subordinadas todas las demás concepciones del mundo. Existe una perspectiva universal, en la que todas las perspectivas son explicadas e incluidas.

11 La primera concepción del mundo es la concepción del mundo de la sensibilidad. Para esta perspectiva lo real sin más es aquello que entra en la competencia de los sentidos. Debe resultar obvio a partir de lo dicho que para Fichte esta visión del mundo no tiene ninguna validez última. Él no encuentra buenas palabras para el empirismo dogmático ni para el hedonismo moral.

12 La segunda concepción del mundo es la de la moralidad. Para esta visión del mundo lo supremo es una ley que ordena, una ley que ordena para un sistema de seres racionales. Esta ley ordena la libertad del individuo de modo racional. La acción arbitraria del individuo es corregida y recortada por el actuar de todos, y en especial no por medio de las acciones concretas, individuales, sino gracias a un imperativo, que establece una relación legal, formal, entre lo individual y la totalidad. Esta es la ley moral, el imperativo categórico de Kant. Esta ley -ésta es la afirmación de Fichte- es aquí lo primeramente real. Es aquello sin lo cual no se da nada. Todo lo que existe es posible por medio de esta ley.

13 La primera concepción del mundo, la de la sensibilidad, describe la concepción usual del mundo y el modo usual de hablar sobre el mundo: lo percibido de modo sensible parece poseer realidad de un modo particular. Pero, ¿cómo debe entenderse esto de que una ley deba ser lo originariamente real? Fichte señala que el entendimiento sano no puede hacer otra cosa que tomar como real aquello que se puede percibir de modo sensible. Pero ¿qué significa esto cuando, por otro lado, la ley moral es lo primeramente real? El mundo es contemplado ahora desde otra perspectiva. En la primera concepción del mundo las cosas están dadas. La segunda concepción del mundo procede de modo diferente. Para ella el mundo consiste en fines, que son elegidos de modo libre. Se actúa de acuerdo con estos fines. La ley moral determina a la libertad y a los fines.

14 La segunda concepción del mundo -así lo enfatiza Fichte- es defendida por Kant en términos de una posición filosófica hasta la Crítica de la razón práctica. Él mismo, Fichte, había defendido esta posición, si bien no como la posición suprema, sino como una posición de la teoría del derecho y la moral. Si no hay aquí una corrección, se da una relativización de la propia concepción anterior. La segunda concepción del mundo no es por cierto falsa sin más, sino más bien insatisfactoria. Su falencia reside en la determinación meramente negativa de la acción. El imperativo de Kant expresa lo que no debe ser hecho. Él apunta sólo a la adecuación de la acción respecto de una obligación, pero sin embargo no busca ni el entusiasmo ni el compromiso de quien actúa. Él determina solamente "que nadie cometa una injusticia y que cada uno únicamente se abstenga de hacer aquello que es contrario a la obligación."7

De allí que la tercera visión del mundo se denomine como el punto de vista de la moralidad verdadera y superior. Mientras que la ley de la segunda concepción del mundo 
únicamente ordena lo que está dado, esto es: coordina la libertad de todos los individuos, la tercera concepción del mundo es productiva, creativa y creadora. Lo primero para esta concepción del mundo es lo santo, lo bueno y lo bello, lo segundo es la humanidad y su determinación de expresar en sí misma la idea de lo santo, lo bueno y lo bello. La ley moral, que es lo tercero en esta visión del mundo, sirve sin embargo como medio para el fin de realizar la verdadera determinación. Ella trae la paz al mundo y a la humanidad, pero sin embargo no puede producir por sí misma la idea positiva -como sí ocurre con la moralidad superior. El mundo sensible es en consecuencia lo cuarto en importancia para esta concepción del mundo, él es sólo la esfera de la acción -tal como lo es para la segunda concepción del mundo. El mundo es considerado en sí mismo algo insignificante, vale como algo sólo para la acción moral.

La cuarta concepción del mundo es la de la religión. Ella consiste en una profundización mayor de aquello que es considerado como lo real. Tal como en la tercera concepción del mundo lo eran las ideas de lo santo, lo bello y lo bueno, aquí también lo es la concepción de que las ideas

no son de ninguna manera nuestro engendro o el engendro de un espíritu, una luz, un pensamiento sin valor en sí mismos, sino que son inmediatamente en nosotros la aparición del ser íntimo de Dios, tal como lo es la luz. (AsL, GA I/9, 110)

El ser íntimo de Dios, la quintaesencia de toda realidad, la realidad sin más, aparece en nosotros, esto es, en las ideas. Con ello lo que es real se convierte en real por medio de lo que es real sin más. Dios, la única realidad, garantiza la realidad de las ideas, de lo santo, lo bueno y lo bello, y finalmente también de modo mediato la realidad de la ley moral y del mundo sensible. Este es el punto de vista de la religiosidad. Para este punto de vista Dios es el concepto central.

El primer principio de la realidad reza, según Fichte, del siguiente modo: "únicamente existe Dios y fuera de él no existe nada." 8 Obviamente este principio es la condición de la vida religiosa, porque el principio expresa la existencia única de Dios. El segundo principio dice: no puede decirse nada sobre el ser íntimo de Dios. El principio: Dios existe sólo conduce a un concepto que es una sombra. A quien pregunta qué es Dios no se le puede responder Dios existe. Aparentemente quien pregunta quiere saber otra cosa diferente del que de la existencia. Aun cuando el principio es complementado por medio de la formulación de que Dios sería absoluto (a partir, por medio y en sí mismo), la respuesta sigue siendo insatisfactoria. Porque éste ser de Dios a-partir-de-sí, por-sí y en-sí se presenta como la "forma fundamental de nuestro entendimiento y no expresa

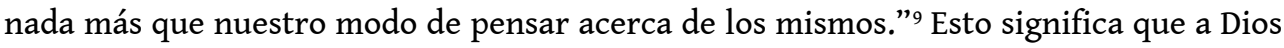
le corresponde lo mismo que al ser de la Doctrina de la Ciencia. El decir "existe" es sólo una objetivación, surgida a partir de la forma fundamental de la consciencia que no puede ser trascendida, pero que no es aplicable a Dios, al modo en que Él es en sí mismo. Un Dios meramente existente es nada, tal como el ser es nada: "en la medida en que decimos: Dios existe, Él es justamente nada para nosotros y por medio de este decir se convierte en nada." ${ }^{10}$

19 Ahora el tercer principio muestra que ciertamente Dios no puede ser conocido, sin embargo entra en la vida: "nosotros mismos somos esta su vida inmediata." ${ }^{11}$ Del mismo modo en que el decir existe objetiva a Dios, lo convierte en un objeto y en algo extraño, el hacer, la vida son el presente inmediato de Dios.

20 Para Fichte es algo fuera de toda duda que Dios no se escapa de sí mismo. Él no es el misterio que no quiere descifrarse a sí mismo. La consciencia es lo que se entromete en 
el camino, porque la función de la consciencia es representar, reproducir, formar. Esta función hace que el ser no aparezca en cuanto tal, sino sólo en la forma del mismo. En la medida en que la consciencia intente pensar Dios, fracasará. Sólo podrá afirmar que Dios existe, esto es determinar un concepto sombrío y vacío de Dios. Le está reservado a la religión el ir más allá del "Dios es" y llegar a Dios mismo, y, por cierto, de modo no discursivo ni por medio del concepto:

en la medida en que lo que hace, vive y ama el hombre santo no aparece más en sombras o cubierto con una funda, sino en una vida propia inmediata y potente; y la pregunta que no puede responderse a partir del concepto sombra vacío de Dios: qué es Dios, es aquí respondida de la siguiente manera: Él es aquello que hace en cuanto que es su resultado y que es motivado por Él. (AsL, GA I/9,111)

El decir se ha convertido en la religión en un hacer. Esta perspectiva puede ser caracterizada como mística, porque ella termina totalmente en la ejecución de la acción. Si se le agrega que Fichte piensa siempre a esta acción al mismo tiempo también como política, en esta "religión" se llega a una unión de la moralidad y la religión como una forma de vida propia.

Finalmente en la concepción de Fichte sigue una quinta visión del mundo, como la suprema y absoluta. Es la filosofía o la ciencia. Ella es una ciencia una, absoluta y completa en sí misma. Ella muestra de qué modo lo múltiple se puede retrotraer a lo absoluto, esto es a la unidad trascendental -lo que representaron las lecciones tercera y cuarta de la AsL de modo popular. De allí que la ciencia vaya más allá de la mera facticidad. Ella no muestra solamente que todo lo múltiple está fundamentado trascendentalmente en lo absoluto. Ella se concentra sobre todo en el modo en que esta relación se produce. Fichte denomina a esta relación como genética en oposición a la facticidad del que. Esta perspectiva genética es ciencia. El reconocimiento del que fáctico es, por el contrario, una mera opinión. "La religión sin ciencia es en algún punto una mera fe, si bien es inalterable: la ciencia suprime toda fe y la convierte en contemplación"..$^{12}$ Con ello Fichte por un lado corrige a Kant, quien señaló en su Crítica de la razón pura que quería restringir el saber para dar lugar a la fe; por otro lado, él critica a Pablo, quien en la Segunda Epístola a los Corintios establece: "nosotros caminamos en la fe, no en el mirar." ${ }^{13}$ Este mirar de la ciencia y la filosofía no es en Fichte una visión mística del fundamento del mundo, sino: teoría (del griego $\theta \varepsilon \omega \rho \varepsilon i ̃ v$, mirar). Se trata de un argumentar que puede ser probado racionalmente y que se funda en sí mismo. ${ }^{14}$ La ciencia no es como la religión, la cual es una realización del ser y el existir divinos liberada de todo condicionamiento epistemológico y lingüístico, sino que rinde cuentas ante sí misma de lo que hace.

Fichte permanece sin embargo comprometido con la filosofía trascendental. El carácter perspectivista de todo conocimiento y acción no se puede suprimir por principio. Él piensa como Kant que el conocimiento no puede ampliarse más allá de sus límites, sin quedar enredado en contradicciones. Este perspectivismo identifica la pertenencia de una filosofía a la modernidad. Esto puede mostrarse fácilmente en relación con la posición fundamental de Fichte respecto de la división entre el derecho y la moral. ${ }^{15} \mathrm{En}$ la Doctrina de la Ciencia, la philosophia prima de Fichte, la subjetividad perspectivista es fundamentada por medio de un movimiento de pensamiento performativo. La Doctrina de la Ciencia muestra cómo lo representado debe ser puesto como límite y restricción del conocimiento únicamente a partir de la auto-transparencia del conocimiento como representación. La realidad pierde, desde un punto de vista trascendental, el carácter de lo dado. La teoría de Fichte apunta a poder fundamentar también por qué el mundo 
se nos aparece como dado, como una concepción más allá del idealismo y el empirismo. El punto de unificación del conocimiento es allí un hecho encontrado fácticamente y sin embargo no deducible. Por el contrario, la pluralidad del mundo -y su realidad para nosotros- es un asunto de la comprensión que necesita de una explicación y que puede ser explicado únicamente por el camino trascendental. Fichte no aboga de ninguna manera por un constructivismo idealista, según el cual el mundo es lo que nosotros hemos hecho de él. Él defiende más bien un realismo reflexivo, de acuerdo con el cual el mundo es como es, pero nosotros podemos conocer además a partir de qué fundamento existe y por qué nosotros debemos transformarlo.

\section{La teoría de Fichte de la imagen como fundamento de su teoría de la perspectiva}

Fichte comienza a desarrollar su teoría de la imagen en la Doctrina de la Ciencia en las tres versiones del año 1804 y luego casi en cada versión siguiente de la Doctrina de la Ciencia la encontramos. La Doctrina de la Ciencia de 1805 ocupa una posición particular en la totalidad de la obra de Fichte: ante todo debe saberse que Fichte en aquel tiempo, es decir en los años 1804/05, expuso cuatro veces sobre la Doctrina de la Ciencia de modo seguido. La Doctrina de la Ciencia de 1805 es la última en esta serie, y uno puede suponer que ella es una especie de resultado de las precedentes. ${ }^{16}$ Junto a las caracterizaciones de la consciencia, a saber como representación, manifestación o imagen, se agrega aquí una más: la caracterización como existencia (Existenz).

Por medio de este concepto de existencia Fichte hacía referencia a la íntima afinidad entre el ser y la consciencia. La existencia es entendida por Fichte, de acuerdo con su Doctrina de la Ciencia, como aquella forma en la que el ser está manifiesto. En las lecciones sobre El camino a la vida bienaventurada, expuestas poco tiempo después, existencia aparece como Da-sein. Y, como en casi todas las Doctrinas de la Ciencia tardías, Fichte denomina a la consciencia como imagen (Bild). La consciencia en cuanto imagen es, dicho en el estilo telegráfico típico de los manuscritos de las lecciones de Fichte:

la imagen, que se pone a sí misma y se forma como imagen, en contraposición con la no-imagen, ser en sí, por sí y a través de sí misma: por medio de lo cual ellos deben estar inclinados desde su aparición a admitir que esta imagen es conocimiento en su cualidad más universal [...]. (WL-1805 GA II/9, 186)

La imagen, que se pone a sí misma como imagen: esta fórmula muestra la fuerza constructiva de la imagen. La imagen se forma a sí misma como imagen. Traducido a la terminología del conocimiento, esto significa: el conocimiento se pone a sí mismo como conocimiento, se forma a sí mismo como conocimiento, se hace a sí mismo en esta relación con lo que él es: conocimiento. El contenido del conocimiento es determinado como ser. La reflexión de Fiche dice como sigue: el ser, que es en su cualidad más universal aquél ser-en-sí-por-sí-a-través-de-sí, en una palabra lo absoluto, puede ser pensado o conocido por fuera de la forma, por lo que el pensar y el conocer, el saber, es justamente esta forma. Pero entra en contradicción con el contenido de que lo absoluto es pensado por fuera de toda forma. El concepto de imagen soluciona para Fichte este problema de toda teoría que tenga una amplia fundamentación filosóficotrascendental. La imagen debe entenderse a sí misma como imagen. Luego la imagen se determina a sí misma no sólo en tanto que imagen, sino como imagen de aquello que 
ella no es. En la medida en que la imagen se entiende a sí misma en cuanto que imagen, se pone a sí misma frente a una no-imagen, una no-imagen cuya imagen es la imagen. De este modo la imagen se forma a sí misma no sólo como imagen, sino que forma también la no-imagen, de la cual es imagen. Esto significa, traducido a la terminología del conocimiento: el conocimiento debe mirarse a sí mismo como conocimiento, lo que es posible para el conocimiento, porque el conocimiento a la vez es un autoconocimiento posible, una conciencia que siempre al mismo tiempo es una autoconsciencia posible. Al ocurrir esto, el conocimiento sabe que es siempre conocimiento-de-algo, este algo es sin embargo siempre un ser en su cualidad universal. De aquí puede concluirse: la imagen en cuanto que imagen pone el ser. Esta es una concepción constructiva de la imagen, una concepción constructiva del conocimiento.

Sin embargo tenemos aquí a la imagen no sólo como imagen, sino como una imagen de la imagen, en esta auto-caracterización de la imagen. En el pensamiento imagen como imagen reside al mismo tiempo el pensamiento imagen de la imagen. Esta nueva imagen, que no es más una imagen de la no-imagen, es independiente frente al ser, porque es una "imagen de relación que se hace a sí misma y por sí misma de modo absoluto coincidiendo con el formarse del Yo." ${ }^{17} \mathrm{La}$ imagen es un formarse verbal que es dinámico en sí. Como ya se ha mostrado en otro lugar, ${ }^{18}$ Fichte se interesa por el aspecto pedagógico del concepto de formar, que es confirmado por numerosos escritos y manuscritos tardíos. Formarse a sí mismo en cuanto que imagen es siempre al mismo tiempo una tarea de la formación (Bildung). Este proceso de formación debe motivar al individuo en la totalidad de sus acciones vitales. Aquello que cada uno de nosotros es, conocimiento, independientemente de la forma rudimentaria en la que se dé, está mediado conceptualmente por las metáforas de la imagen con el ámbito de lo práctico, un ámbito que en Fichte está determinado siempre por medio de la autonomía, es decir de la auto-formación.

En la auto-relación de esta imagen está contenido finalmente el que no sólo debe darse una imagen de la imagen, sino también una imagen de la imagen de la imagen. Como se mostró, la imagen de la imagen surge por medio del juicio, esto es por medio de la reflexión. Siempre que yo conozco, conozco algo. El conocimiento no está nunca simplemente vacío. Para alcanzar la Doctrina de la Ciencia uno debe abstraerse, en particular del conocer del conocer-algo. Lo que queda es el conocimiento mismo, que no aparece en ningún conocimiento-de-algo y sin embargo es su condición de posibilidad. Este conocimiento es imagen de la imagen, conocer del conocer-algo. Si se reflexiona de nuevo sobre este conocimiento, resulta de ello el conocimiento de la Doctrina de la Ciencia, conocimiento que Fichte caracteriza como conocimiento del conocimiento y que, en la medida en que el conocimiento es siempre conocimiento-dealgo, Fichte puede caracterizar como conocimiento del conocimiento del conocimiento. Con estas ideas se cierra al mismo tiempo la Doctrina de la Ciencia. Todos los estadios posibles del conocimiento se reproducen entonces en el conocimiento. El fundamento último mismo del conocimiento es explicitado en una auto-relación completa. El conocimiento de la Doctrina de la Ciencia es entendido como una imagen de la imagen de la imagen. Al mismo tiempo el concepto de imagen pierde su significado objetivo. Si la primera imagen representa un objeto, totalmente en el sentido de re-presentación, la imagen de la imagen ya es entonces una mera reflexión, un juicio, que sólo puede ser producido por medio de una abstracción del objeto. La actividad de la reflexión, su 
ejecución, es irrenunciable. ${ }^{19}$ De este modo la imagen de la imagen no es otra cosa que un formarse a sí mismo como imagen. Pero también en esta reflexión el objeto es considerado como un acto de formar, y con ello le es robada su objetualidad y es reformulada como un acto constructivo del conocimiento. En última instancia, esto vale también para la imagen de la imagen de la imagen, que sólo se conserva en un experimento permanente de la Doctrina de la Ciencia.

\section{Filosofía trascendental: de la representación a la presentación.}

29 Frecuentemente las soluciones a los problemas son extraordinariamente exitosas porque con ellas pueden abrirse muchas cerraduras diferentes. Una tal llave es el famoso Yo de la primera Doctrina de la Ciencia de Fichte, del Fundamento de toda la Doctrina de la Ciencia, de 1794/95..$^{20}$ Ya esta primera Doctrina de la Ciencia se sostiene en la idea de Fichte del Yo desde una perspectiva trascendental: el conocimiento precede al ser. Este yo que se pone a sí mismo no significa ante todo otra cosa que la inmanencia total de la consciencia en la unidad. Es una expresión de la convicción de Fichte de que admitir un mundo de cosas independiente del conocimiento constituye un malentendido de las condiciones de posibilidad constitutivas que están por detrás suyo. Fichte reduce por lo tanto la teoría kantiana de las dos fuentes a la teoría de una fuente. En lugar de la dualidad de sensibilidad y entendimiento, Fichte establece ahora únicamente el Yo. Pero ¿cómo debería explicarse a partir del Yo el hecho de que para todos nosotros aparezca un mundo externo como mundo externo? A partir de lo dicho debería estar claro que el fundamento para Fichte no puede radicar en el mundo exterior, sino sólo en el Yo. Por lo tanto, Fichte encuentra en el Yo una forma absoluta e indemostrable del oponer. La fórmula de la disposición fundamental constructivista de la Doctrina de la Ciencia dice entonces: que el Yo se pone frente a un No-Yo. Lo que de todos modos aparece en el mundo exterior en cuanto mundo exterior, es puesto en consecuencia por el Yo. El Yo es lo originariamente activo, es Thathandlung, energía, génesis.

La Doctrina de la Ciencia no es en este sentido ninguna teoría del origen auténtico de nuestro mundo real sino que, de acuerdo con el rasgo de la filosofía trascendental, una filosofía que investiga las condiciones de posibilidad del conocimiento y de la acción. No se trata de la deducción metafísica de la pluralidad a partir de la unidad, sino por el contrario de la remisión de la pluralidad a la unidad.

31 En Jena la Doctrina de la Ciencia tiene dos partes, una teórica y una práctica. La tarea de la parte teórica es la deducción de la representación, lo que significa, desde la terminología de la época, la deducción de los elementos estructurales de la consciencia empírica. Entre ellas se cuentan sobre todo las categorías, así como las formas puras de la intuición, espacio y tiempo. Fichte genera a partir del Yo del comienzo de la GWL, por medio de una forma especial de dialéctica, un proceso genético, en el cual las categorías son deducidas unas luego de otras y a partir de otras. La estructura de la conciencia objetual resulta del juego conjunto de las categorías con las formas de la intuición. Hacia el final de la parte teórica debe llegarse a la conciencia real, un pasaje que podría caracterizarse también como la transformación de meras condiciones de posibilidad en condiciones de realidad. Siguiendo totalmente a Kant, Fichte reconoce en la imaginación una capacidad que media entre la intuición y el concepto puro y, por este 
medio, hace posible la representación; él insiste más enérgicamente que Kant en su función productiva, lo que significa aquí creadora.

La imaginación no produce ningún esquema como en Kant, sino que produce la realidad aparente misma, que en este sentido es imagen, presentación. El concepto de imagen en Fichte apunta a este primer bosquejo de una imaginación. Allí se muestra un momento característico, que aparece en todos los intentos posteriores de Fichte de desarrollar una Doctrina de la Ciencia: la imaginación es una capacidad de producir imágenes, que se niega a sí misma en el proceso de la producción de las imágenes y, por eso, hace posible que la imagen producida aparezca frente a nosotros como un mundo exterior real. Mientras que para Kant la representación aparece aún en primer plano como Repräsentation, en Fichte se transforma en Präsentation. Mientras que Kant marca la cosa en sí como un punto de fuga de la representación, para Fichte ella está completamente borrada. Este es un cambio significativo desde una representación representante hacia una presentante. En la presentación no se da más ese punto de fuga, aquél ancla en algún mundo exterior pensado como real.

La imaginación es para Fichte una capacidad de construir imágenes. Las imágenes producidas no son otra cosa que la realidad. El concepto de imagen adopta un rol totalmente especial, él lleva a cabo una mediación como producción. La imagen no es ilustración, del mismo modo que la representación no es representación de un mundo exterior previo. La imagen es producción de lo reproducido, por lo tanto es un proceso de formación en un sentido eminente, tal como la representación es la producción de lo representado.

\section{Conclusión}

Lo que se ha expuesto hasta aquí habla mucho en favor de ver a Fichte no como un pensador de la unidad pura y de lo puramente absoluto, sino como un pensador de estructuras de fundamentación trascendental-filosóficas. Lo "absoluto" es para él, en última instancia, el punto de la realidad práctica que no puede ser anulado, un pensamiento contrafáctico, que piensa un "absoluto" que en su cómo no puede ser penetrado, puede ser comprendido y transformado en acción sólo en su que. Fichte no determina la certeza del conocimiento a partir de la verdad, sino partiendo de la certeza del conocimiento de su verdad. El ser finito descubre en sí mismo la capacidad de producir un cierto conocimiento. Fichte descubre en el análisis de este conocimiento una estructura fundamental, que no es previa ontológicamente, sino que es inmanente al conocimiento. Este análisis consiste en una teoría que concibe al conocimiento como imagen. Pero la imagen no es para Fichte una representación de contenidos preexistentes, sino producción, presentación, proyección. Por lo tanto, la imagen es "imagen productora", imagen que primero produce aquello de lo que es imagen. Esta función se denomina en la primera Doctrina de la Ciencia imaginación.

Una reacción explícita a esta teoría de la presentación se encuentra en los Estudios sobre Fichte de Novalis. En Novalis el concepto de la imaginación conserva un significado poetológico, sin abandonar empero en principio el concepto de Fichte. Cuando la imaginación produce la materia para el arte, ella produce con esto de hecho una realidad con un contenido de verdad superior, produce ella misma los opuestos entre los que ella media productivamente. 
Este momento aparece en Novalis tanto como en Fichte, con mayor precisión: yendo más allá del primer Fichte. La imaginación, no ya como facultad, sino como mera actividad, no es otra cosa que un estar entre, una relación absoluta, que constituye en primer lugar a los relata. La incompatibilidad entre el yo y el mundo, entre el mundo y el arte, de lo infinito y lo finito, no lleva a la capitulación ante el disenso, aparentemente indisoluble, ni a la anexión violenta por medio de una unidad superior. Porque cada incompatibilidad, sea también entre la diferencia y la identidad, está a la base de la actividad creadora y libre del "estar entre", esto es, de la imaginación productiva.

Al mismo tiempo Novalis ha descubierto una fórmula mágica, gracias a la cual puede abrirse la teoría de la inmanencia de Fichte, orientada a la construcción de un sistema. La teoría del Yo de Fichte desarrolla una presión formidable por medio de evidencias: todo lo que pueda ser conocido debe ser realizado por medio del Yo que pone los principios. Que esto sólo se puede lograr en un aspirar y esforzarse hacia (Streben), y que esta realización sólo reside en un deber, no en un ser, bien puede estar en armonía con la finitud del pensamiento y la acción humanos. Para Novalis la imaginación es aquello que abre esta cerrazón preexistente. Ahora, esta pluralidad no sólo es posible, sino que es lo único posible. No llama la atención que esta concepción tome su paradigma del arte, porque un pluralismo de perspectivas sin unidad debe renunciar a la concepción filosófica en el sentido de Fichte. La filosofía pasa al arte. El mundo se vuelve un fragmento, el conocimiento, poesía.

\section{Bibliografía}

Asmuth, Ch. Wissenschaft und Religion. Perspektivität und Absolutes in der Philosophie Johann Gottlieb Fichtes", en: Fichte-Studien 8 (1995), pp. 1-19.

"Transzendentalphilosophie oder absolute Metaphysik? Grundsätzliche

Fragen an Fichtes Spätphilosophie”, en: Fichte-Studien 31 (2007), pp. 45-58.

"Von der Urteilstheorie zur Bewusstseinstheorie. Die Entgrenzung der

Transzendentalphilosophie”, en: Fichte-Studien 33 (2009), pp. 221-249.

"Bild des Bildes des Bildes: Fichtes radikal konstruktivistische Bildtheorie.“

en: Neuber, S. \& Veressov, Ro. (eds.), Das Bild als Denkfigur, München: W. Fink, 2010, pp. 153-165.

"Der Staat und die Sittlichkeit", en: Der Staat als Mittel zum Zweck. Fichte über Freiheit, Recht und Gesetz. Zöller, G. (ed.), (Staatsverständnisse; 39) Mannheim: Nomos, 2011, pp. 91-109.

„,Das Wesen als Reflexion in ihm selbst - Fichte in Hegels Wesenslogik“, en:

Wunsch, M. (ed.), Von Hegel zur philosophischen Anthropologie. Gedenkband für Christa Hackenesch, Würzburg: Königshausen \& Neumann, 2012, pp. 73-85.

Bertinetto, A. La forza dell'immagine. Argomentazione trascendentale e ricorsività nella filosofia di J. G. Fichte. Milano/Udine: Mimesis, 2010.

Bochenski, J. M., “On logical »relativism«”, en: Axiomathes 2 (1993), pp. 193-209.

Burri, A. \& Freudiger, J. (eds.), Relativismus und Kontextualismus. Festschrift für Henri Lauener, Amsterdam/ Atlanta: Rodopi, 1993.

Class, W. \& Soller, A. K. Kommentar zu Fichtes , Grundlage der gesamten Wissenschaftslehre, Fichte-Studien. Supplementa 19, Amsterdam/New York: Rodopi, 2004.

Revista de Estud(i)os sobre Fichte, 6 | 2013 
Cramer, W., Gottesbeweise und ihre Kritik. Prüfung ihrer Beweiskraft. Frankfurt a. M.: Klostermann, 1967.

D’Agostini, F., Analitici e Continentali. Guida alla filosofia degli ultimi trent'anni, Milano: Raffaello Cortina 1997.

D’Agostini, F., Disavventure della verità, Torino: Einaudi, 2002.

Falk, H. H. "Existenz und Licht. Zur Entwicklung des Wissensbegriffs in Fichtes Wissenschaftslehre von 1805”, en: Fichte-Studien 7 (1995), 49-57.

Ferrer, D. “O significado do conceito em Fichte (1805)", en: Revista Filosofica de Coimbra 8 (1995), 407-438

"Der Begriff der Existenz und der Gang der Wissenschaftslehre 1805", en: Fichte-Studien 17 (2000), 259-267.

Gerten, M. (ed.) Fichte-Studien 34 (2009), tema: Fichte in Erlangen.

Holz, H. H., Einheit und Widerspruch. Problemgeschichte der Dialektik in der Neuzeit, II, Stuttgart/Weimar: Metzler, 1998.

Janke, W. “'Das Wissen ist an sich die absolute Existenz'. Der oberste Grundsatz in Fichtes 4. Vortrag der Wissenschaftslehre, Erlangen im Sommer 1805", en: Perspektiven der Philosophie. Neues Jahrbuch 22 (1996), 189-230;

Johann Gottlieb Fichtes „Wissenschaftslehre 1805“. Methodischsystematischer und philosophiegeschichtlicher Kommentar. Darmstadt: 1999;

Jiménez R., M. "Der aporetische Begriff der Erscheinung des Absoluten bei Fichtes WL 1805”, en: Fichte-Studien 20 (2003), 185-199.

Rescher, N., Pluralism: Against the Demand for Consensus, Oxford: Clarendon Press, 1993. Taylor, Ch., Philosophical Arguments, Cambridge MA: Harvard University Press, 1995. Traub, H., "Vollendung der Lebensform. Fichtes Lehre vom seligen Leben als Theorie der Weltanschauung und des Lebensgefühls", en: Fichte-Studien 8 (1995), pp. 161-191.

Tully, J. \& Weinstock, D. M., Philosophy in an Age of Pluralism. The Philosophy of Charles Taylor in Question, Cambridge: Cambridge University Press, 1995.

\section{NOTAS}

1. Para un análisis de las diversas formas de pluralismo, ver D’Agostini 1997: 167-201. Para una precisión de las relaciones entre el pluralismo y la verdad ver D'Agostini 2002: 249 ss. Para la afinidad entre el pluralismo y el relativismo, ver entre otros, Burri \& Freudiger 1993: 159-174; Bochenski 1993; Rescher 1993; Taylor 1995 y James 1995.

2. Cramer 1967: 8-11.

3. Cf. Asmuth 2009.

4. Asmuth 2007.

5. BM, GA I/6, 252.

6. Acerca de la teoría de las visiones del mundo véase: Asmuth 1995 y Traub 1995.

7. AsL, GA I/9, 107 ss.

8. AsL, GA I/9, 110.

9. AsL, GA I/9, 110.

10. AsL, GA I/9, 111.

11. AsL, GA I/9, 111. 
12. AsL, GA I/9, 112.

13. KrV B XXX, Segunda Epístola de Pablo a los Corintios 5, 7.

14. Para una posición contraria a lo aquí afirmado véase Holz 1998: 283-310.

15. Cf. Asmuth 2011

16. Cf. Bertinetto 2010; Falk 1995; Ferrer 1995 y 2000; Gerten 2009; Janke 1996 y 1999; JiménezRedondo 2003.

17. WL-1805 GA II/9, 192.

18. Cf. Asmuth 2010: 153-165.

19. Acerca del rol de la reflexión en Fichte y Hegel véase Asmuth 2012

20. Cf. Class \& Soller 2004

\section{RESÚMENES}

In this paper I want to critically analyze from the background of the problem of perspectivism and pluralism Fichte's theory of knowledge. I will focus on Fichte's theory of worldviews, developed in The Way Towards the Blessed Life (1806) and on the versions from 1794 and 1805 of his doctrine of knowledge. I will argue that Fichte's doctrine of knowledge is a theory of the image and consists in a transcendental-philosophical constructivism. I will also claim that the doctrine of knowledge is not a theory about the real origin of the real world, but a philosophy that investigates the conditions of possibility for knowledge and action. As a conclusion I will show that my interpretation of Fichte's philosophy as a constructivist theory of image enables a better understanding of Novalis' reception of Fichte's philosophy.

ÍNDICE

Keywords: perspective, pluralism, image, imagination, worldview, constructivism, Novalis

\section{AUTORES}

\section{CHRISTOPH ASMUTH}

Technische Universität Berlin 